\title{
EXPERIMENTAL FOREIGN EXCHANGE MARKETS
}

\author{
ERIC O'N. FISHER Ohio State University, USA \\ FRANK S. KELLY IUPUI, USA
}

\begin{abstract}
The paper analyzes experimental markets where subjects buy and sell two different assets. The assets' properties vary across treatments, and their relative price is the exchange rate. Although both assets uniformly exhibit bubbles, the exchange rate satisfies cross-currency arbitrage. There is no evidence of a positive risk premium in these markets, and almost all subjects' forecasts of the exchange rate are rational.
\end{abstract}

\section{INTRODUCTION}

The literature on foreign exchange markets has extensive theoretical, empirical and historical sides, but there has been almost no experimental work in this area. Since exchange rates are relative asset prices, foreign exchange experiments fall within the purview of the growing literature on asset markets in the laboratory. ${ }^{1}$ The first strand of this work replicates a static environment and confirms the predictions inherent in using rational expectations as an equilibrium concept. Forsythe et al. (1982) is a classic example, and Plott and Sunder $(1982,1988)$ are other important papers. ${ }^{2}$ The second strand focuses on dynamic environments, and the seminal paper is by Smith et al. (1988). These experimental markets almost always exhibit price bubbles. ${ }^{3}$ The asset's price is initially below its fundamental, rises above it in the middle periods, and crashes down to it in the last few periods. ${ }^{4}$

\footnotetext{
${ }^{1}$ Davis and Holt (1993) surveys much of the work in experimental economics in general, and Sunder (1995) surveys the literature on asset market sessions in particular.

${ }^{2}$ O'Brien and Srivastava (1991) replicate static but informationally complex environments with several assets, and their work is closely related to our own. They find less support for the predictions of rational expectations theory than is the norm, but they also show that asset prices satisfy cross-equation restrictions.

${ }^{3}$ A bubble is any systematic deviation of an asset's price from its fundamental, and a rational bubble further satisfies some intertemporal arbitrage condition, typically an Euler equation. Flood and Hodrick (1990) surveys the nascent literature on testing for bubbles in foreign exchange markets in the field.

${ }^{4}$ Smith et al. (1988) argue implicitly that bubbles arise because of expected capital gains, but Sunder (1995) suggests that they may be artifacts of learning. King et al. (1993) find bubbles even with short selling and futures markets, and van Boening et al. (1993) have demonstrated it also occurs in call markets.
} 
Almost all the literature using field data from the modern period of floating exchange rates emphasizes that the stochastic processes driving exchange rates appear not to be stationary. For example, Mark (1990) and Fisher and Park (1991) show that the many bilateral exchange rates have unit roots, and most modern theories emphasize that asset prices follow martingales. Hence, it is appropriate to design experiments where the market is not stationary. This consideration led us to adopt the framework of Smith, Suchanek and Williams.

We add one basic element to their design: simultaneous trading in two assets. In some treatments, the differences between these assets is spurious; in others, one asset is riskier than the other, or one pays twice the expected dividend of the other. Of course, asset markets by their very nature allow for intertemporal arbitrage. In foreign exchange markets, as in our experiment, traders also face the possibility of cross-asset arbitrage. Our main conclusion is that subjects get the cross exchange rate right.

Our markets are oral double auctions where traders sell assets for dollars and dollars for assets. Hence a trader taking advantage of a perceived arbitrage opportunity must, for example, sell blue assets for dollars and then subsequently buy red assets with dollars. This may seem strange at first blush, but modern foreign exchange markets work exactly in this manner. ${ }^{5}$ Foreign exchange is traded in the field in over-the-counter markets made by large commercial banks. But the informational efficiencies inherent in an oral double auction create laboratory markets whose properties are quite similar to those of the thick foreign exchange markets in the field.

It is important to emphasize that there are only two independent exchange rates in our experiments: the dollar prices of the blue and red assets. The crux of our results is that the implied blue-red cross-rate is well behaved. This finding is all the more striking because the dollar prices of both assets are significantly different from their fundamentals. Thus bubbles arise in each market, but they are not independent!

Why are these dividend-bearing assets foreign exchange? These assets capture two of the traditional roles of money: transactions and store of value. First, an asset's dividend can be interpreted as the utility of having that currency on hand when exports are invoiced in the home country's currency. Then a relatively high realization of the blue dividend is an inflation differential favoring the purchase of blue goods. Second, consider money as a store of value. A trader whose portfolio consists only of dollars has a certain return, and one who is long the blue or red asset has a risky portfolio, just like an arbitrageur in the field with an open position in foreign exchange. If the blue asset is expected to be a better risk-adjusted store of value than the red, then there will be an immediate appreciation of the blue currency. This is one of the basic predictions of monetary models in which several assets serve as stores of value.

Foreign exchange markets are perhaps the thickest financial markets in the world, with continuous trading occurring in geographically distinct markets.

\footnotetext{
${ }^{5}$ See Chorafas (1992, p. 57) or Grabbe (1986, p. 63).
} 
Their volume of transactions is many times that of the New York Stock Exchange. Moreover, only a very small fraction of this trading has to do with buying and selling currencies to service the needs of importers and exporters. Almost all the trading in these markets is based upon arbitrageurs' expectations about short-run reactions of each other's trading strategies to exogenous changes in interest rates or intervention by central banks. Thus an experiment in which traders face uncertainty only about each other's endogenous pricing of assets actually captures foreign exchange markets in the field quite well.

Our hypotheses about these exchange rates fall into three categories. First, we examine arbitrage across time. Although a simple notion of equilibrium implies that assets are priced according to their expected dividends, there is overwhelming evidence of bubbles in both markets. Second, we examine arbitrage across assets. We find that bubbles in each market are positively correlated and hence that simple economic theory predicts the exchange rate fairly well. Also, we show that excess demand in one market only drives bubbles in both markets, although it is not clear a priori if activity in the blue or red asset market creates bubbles in both markets. Third, we examine subjects' attitudes toward risk and their abilities to forecast. We find some evidence for risk-loving behavior in these markets. Also, our subjects are typically able to forecast the exchange rate one period ahead fairly well. In sum, we find an interesting amalgam of simple rational behavior (because the exchange rate is fairly well behaved) and speculative behavior (because asset bubbles are the norm, not the exception).

The rest of this paper is structured as follows. The second section discusses eight hypotheses of any theory of exchange rates. The third section describes the laboratory markets and summarizes the treatments, and the fourth gives details of the experimental procedures. The fifth section reports our results, and the sixth gives a brief conclusion.

\section{HYPOTHESES}

Let $d_{s, j}$ be the random dividend of asset $j$ at time $s$ and $T$ be the terminal period; then

$$
f_{t, j}=E\left[\sum_{s=t}^{T} d_{s, j}\right]
$$

denotes that asset's "fundamental" at time $t$, where this expectation is taken with respect to the market's information set at the beginning of the period. No discount factor enters this expression because each period last only six minutes! Now let $p_{t, j}$ be the price of the $j$ th asset at time $t$. We study the bubble component of asset prices:

$$
\left(p_{t, j}-f_{t, j}\right) / f_{t, j}
$$


where the definition in (1) divorces our data from an obvious dependence on time.

Of course, there is no trader-specific induced valuation for these assets. Thus, if the agents are Bayesians with common priors who hold rational expectations, then the unique equilibrium trading strategies would have agents with different attitudes towards risk trading in the first period and no activity after that. This simple observation informs our first hypothesis.

HYPOTHESIS 1. There are no bubbles in either asset market.

The second hypothesis is based upon the assumption that the subjects satisfy a simple version of cross-asset arbitrage, even if there are bubbles in these markets.

HyPOTHESIS 2. The cross exchange rate is near its theoretical value.

The laboratory allows one to design a system in which the two assets cannot have different ex post rates of return in any state of the world. It is thus possible to examine Friedman's (1953) notion that flexible exchange rates are no more inherently unstable than fixed exchange rates. Allowing for differences in the distributions of the asset prices across treatments, we test an even more general idea.

HyPOTHESIS 3. The distributions of the bubble components are identical under fixed and flexible exchange rates.

It is also possible to test whether a risky asset trades for a lower price than a safe asset. This thesis is at the center of much of theoretical and empirical discussion on the exchange rate risk premium.

HyPOTHESIS 4. There is an exchange-rate risk premium.

The excess of bids over offers may be a good predictor of the difference between this period's and next period's price for the $j$ th asset. Accounting for the determinant change in an asset's fundamental, Smith et al. (1988) found a strong correlation between $p_{t+1, j}-p_{t, j}$ and a measure of lagged excess demand. This leads us to analyze the following.

HYPOTHESIS 5. The change in an asset's price is correlated with the excess of bids over offers, lagged one period, in its own market only.

This hypothesis is tested by running a system of two regressions for each session.

We are interested in the interaction between the markets for blue and red assets, and thus examine the likelihood of runs in either of the markets. There has been some evidence that traders in the field occasionally follow fads in one currency or another. Since both markets are open at all times, it is natural to 
assume that a bid or offer is equally likely to occur in either market. Thus we analyze the following.

HYPOTHESIS 6. Market activity is distributed randomly across either market.

In this genre of asset market experiments, the only treatment effect found consistently to mitigate the effect of bubbles is the repeated use of the same group of experienced traders. Hence, we posit the following.

HYPOTHESIS 7. The repeated use of the same group of experienced traders entails that asset prices trade nearer their fundamental values in the third repetition of the session.

Finally, exchange rate forecasts are at the center of a large literature on the empirical validity of uncovered interest parity. This literature typically assumes that there is a representative agent and then emphasizes that the expected spot exchange rate, adjusted for a risk premium, is an unbiased predictor of the actual spot rate; otherwise agents could make arbitrage profits by holding open positions.

HYPOTHESIS 8. Each trader's forecasts of the exchange rate are unbiased.

\section{THE EXPERIMENTAL DESIGNS}

The most important aspect of the experimental design is that subjects can trade blue or red assets for cash or they can trade cash for blue or red assets. This design captures foreign exchange markets in the field more realistically than other studies, where agents have traded one fictitious asset for another and then are told at the end of the session how much their notional assets are worth in dollars. ${ }^{6}$

Each session consisted of markets for two assets traded simultaneously. There was a fixed supply of at least one blue asset and one red asset per trader. The markets were conducted by hand as oral double auctions. The bids and offers for the blue asset were displayed on the left blackboard, and those in the market for the red asset was on the right blackboard. Each session lasted 15 periods, and dividends were paid at the end of each period. Periods lasted for six minutes, and the subjects were warned when there was one minute and when there were 30 seconds left in the trading period.

The dividends were discrete random variables with equiprobable outcomes, and the realized dividends increased the working capital of a trader holding assets at the end of a period. Agents were given heterogeneous endowments of

\footnotetext{
${ }^{6}$ For example, Noussair et al. (1997) examine a cash-in-advance economy with two countries and two currencies. They follow the convention that goods are priced in the exporter's currency, but their subjects were paid in guilders or dollars according to an exchange rate that was part of the design. Arifovic's (1996) subjects earned utils that were converted into dollars at a fixed rate in each period.
} 
Table 1. Treatment parameters

\begin{tabular}{|c|c|c|c|}
\hline Experiment, date and place ${ }^{\mathrm{a}, \mathrm{b}}$ & Trader types ${ }^{\mathrm{c}}$ & Endowments & Description of the dividends \\
\hline \multicolumn{4}{|l|}{ Design 1} \\
\hline 1.1, 11 November 1993 , OU (0) & I (2) & 3 blue assets and $\$ 2.25$ & Blue asset: uniform distribution on $\{0,0.08,0.28,0.60\}$ \\
\hline 1.2, 12 November 1993 , OU (0) & II (2) & 2 blue assets and $\$ 5.85$ & Red asset: uniform distribution on $\{0,0.08,0.28,0.60\}$ \\
\hline \multirow[t]{4}{*}{ 1.3, 11 January 1994 , OSU (0) } & III (2) & 1 blue asset and $\$ 9.45$ & \\
\hline & IV (2) & 3 red assets and $\$ 2.25$ & The assets' dividends are independently distributed. \\
\hline & $\mathrm{V}(2)$ & 2 red assets and $\$ 5.85$ & \\
\hline & VI (2) & 1 red asset and $\$ 9.45$ & \\
\hline \multicolumn{4}{|l|}{ Design 2} \\
\hline \multirow[t]{6}{*}{ 2.1, 15 April 1994, OSU (7) } & I (2) & 3 blue assets and $\$ 2.25$ & Blue asset: uniform distribution on $\{0,0.08,0.28,0.60\}$ \\
\hline & II (2) & 2 blue assets and $\$ 5.85$ & Red asset: uniform distribution on $\{0,0.04,0.14,0.30\}$ \\
\hline & III (1) & 1 blue asset and $\$ 9.45$ & \\
\hline & IV (2) & 3 red assets and $\$ 7.65$ & The assets' dividends are perfectly positively correlated. \\
\hline & $\mathrm{V}(2)$ & 2 red assets and $\$ 9.45$ & \\
\hline & VI $(1)$ & 1 red asset and $\$ 11.25$ & \\
\hline \multicolumn{4}{|r|}{ ( } \\
\hline $3.1,12$ January 1994, OSU (0) & Same as design 1 & Same as design 2 & Same as design 2 , but the assets' dividends are independently distributed. \\
\hline 3.2, 28 January 1994 , OSU (0) & & & \\
\hline
\end{tabular}


/5_3/y141/makeup/y141.3d

4.1, 22 February 1994, OSU (1)

4.2, 1 March 1994, OSU (5)

4.3, 4 March 1994, OSU (4)

Design 5

5.1, 6 May 1994, OU (7)

5.2, 20 May 1994, OU (9)

\section{Design 6}

6.1, 2 March 1994, OU (0)

6.2, 7 March 1994, OU (11)

6.3, 9 March 1994, OU (11)

\section{Design 4}

Same as design 1

3 blue assets and $\$ 2.75$

2 blue assets and $\$ 6.50$

1 blue asset and $\$ 10.25$

3 red assets and $\$ 2.75$

2 red assets and $\$ 6.50$

1 red asset and $\$ 10.25$

Same as design $1 \quad$ Same as design 4

Same as design 1

I (2)

II (2)

III (2)

IV (2)

$\mathrm{V}(2)$

VI (1)
Blue asset: uniform distribution on $\{0,0.50\}$

Red asset: uniform distribution on $\{0.20,0.30\}$

The assets' dividends are independently distributed.

Same as design 4 , but the traders are asked to forecast the exchange rate.

Same as design 1

${ }^{a}$ OU denotes Ohio University, and OSU denotes the Ohio State University. There was only one type-III trade and one type-VI trader on 11 January 1994.

${ }^{\mathrm{b}}$ The number of super-experienced traders is shown in parentheses.

${ }^{\mathrm{c}}$ The number of traders is shown in parentheses. 
these assets and dollars, and no short sales were permitted. ${ }^{7}$ The expected values of the agents' endowments were all equal; hence traders who were initially endowed with three assets had fewer dollars than did those who had only one asset. At the beginning of each period, the experimenter announced the maximal, minimal, and expected value for a blue asset and the same announcement was made for a red asset. These numbers were written prominently on the blackboard, and running histories of the dividends were displayed in plain sight.

The sessions were conducted at Ohio University and the Ohio State University between November 1993 and May 1994. Almost every session had 12 subjects drawn from the population of undergraduate and graduate students taking economics courses at those two institutions. Each subject had participated in a prior training experiment with induced supply and demand schedules. In the initial sessions, none of the subjects had experience in experimental assets markets. Several later sessions included traders who had participated in an asset market from an earlier treatment. Each of these superexperienced traders was identified publicly several times during the reading of the instructions to the subjects. ${ }^{8}$

The subjects were paid the value in dollars of their working capital at the end of the fifteenth period, and no extra credit or other nonmonetary inducement was offered. The assets held at the end of the session had no value. The students were also paid an extra two dollars for arriving on time at the site, but this money was not a part of their working capital. Their expected earnings were about $\$ 16$, and the sessions ran for approximately two and a half hours. Their actual earnings ranged from $\$ 4$ to $\$ 55$ for a single session.

Table 1 summarizes the parameters underlying the six treatments. In design 1, there were six types of traders distinguished by their initial endowments, each of which had an expected value of $\$ 13.05$. The dividend of the blue asset was a random variable whose support had four elements $(\{\$ 0, \$ 0.08, \$ 0.28$, $\$ 0.60\}$ ), each occurring with probability $1 / 4$. The dividend for the red asset was an independent and identically distributed random variable; hence each expected dividend was $\$ 0.24$. Note that there is no difference between the blue and red asset in de]sign 1.

In design 2 , the blue dividend had the support $\{\$ 0, \$ 0.08, \$ 0.28, \$ 0.60\}$, while the red dividend had the support $\{\$ 0, \$ 0.04, \$ 0.14, \$ 0.30\}$; the two dividends were perfectly positively correlated. Thus, if blue asset pays 60 cents, then the red asset pays 30 cents, or if the blue asset pays 8 cents, then the red asset pays

\footnotetext{
${ }^{7}$ Because these sessions were conducted not by computer but by hand, there were mistaken short sales on two occasions. The ad hoc penalty imposed was that a short seller had to pay the asset's dividend in that period and then also had to cover the short sale from the first offer in the relevant market in the next period. This was not public information.

${ }^{8}$ These super-experienced traders were identified publicly in an attempt to create as much common knowledge as possible. Fisher (1998) constructs a model of these markets in which it is common knowledge that agents have different prior beliefs about the assets' dividends. It would be practically impossible to describe an equilibrium in which some subjects suspected that others had superior information; indeed, the No Trade Theorem of Milgrom and Stokey (1982) might then apply.
} 
4 cents. Now there is a real difference between the blue and red assets, although both assets are equally risky. Since the dividends were perfectly correlated, this design captures the notion of a regime of fixed exchange rates. Design 3 was essentially identical to design 2 , but the dividends were independently distributed. Thus, if the blue dividend is $\$ 0.60$, the red dividend can still be anything in its support $\{\$ 0, \$ .04, \$ .14, \$ 0.30\}$. This design explores uncovered interest parity in a market of floating exchange rates since the expected return from holding an open position in either asset is identical. In either case, the theoretical rate of depreciation of the blue asset in terms of its red counterpart is zero, and the level of the exchange rate is predicted to be one-half.

Designs 4 and 5 used an even simpler dividend whose support had only two elements, each of which occurred with probability $1 / 2$. The support of the (riskier) blue asset was $\{\$ 0, \$ 0.50\}$, and that of the (safer) red asset was $\{\$ 0.20$, $\$ 0.30\}$. These dividends were independently distributed, and the expected value of each trader's endowment was $\$ 14$. These two treatments were designed to explore the risk premium in the foreign exchange market, and they were essentially identical. In design 5, however, the subjects were asked to forecast the end-of-period exchange rate, and the best overall forecaster won an extra dollar at the conclusion of the session.

Finally, design 6 was identical to design 1, but it involved three repetitions of the session with the same group of traders during one week. This design was intended to see whether use of the same group of traders mitigates bubbles in markets with two assets.

\section{EXPERIMENTAL PROCEDURES}

After having been recruited in class and trained in a previous experiment with induced supply and demand, the subjects arrived at a classroom at the scheduled time. The experimenter handed out folders and read the instructions. These were basically a description of the bookkeeping necessary to keep track of one's profits and losses from buying, selling, or holding assets; there was also a short section on probability theory describing the distributions of the dividends for the blue and red assets. The subjects were encouraged to ask questions. The experimenter circulated among the subjects between each of the first few periods to make sure that they were recording their trades and dividend incomes properly. The subjects seemed to learn the requisite accounting and trading skills fairly quickly.

At the beginning of each period, the experimenter wrote on the blackboard the expected value, the maximal value, and the minimal value of holding each asset. Also, there was a running tally on the left blackboard of the bids and offers in the blue asset market and the same for the red asset market on the right blackboard. The top and left borders of the left blackboard were colored with blue chalk, and those of the right blackboard were colored with red chalk.

Since two markets were open simultaneously, a trader raised his hand and might announce, "Trader 4 bids $\$ 1.20$ in the blue market." In order to keep confusion to a minimum, the trader was asked to confirm his acceptance of an 
outstanding bid or offer. A trader could make a bid or offer in only one market each time that he was recognized. As the periods unfolded, the history of realized dividends for each asset was written at the top of the appropriate blackboard. The subjects were publicly reminded at the beginning of each period of the maximum, average, and minimum returns for each asset for the remaining periods. These numbers were written prominently on the relevant blackboards, and they were in plain sight of all traders at all times.

In design 5 the traders were asked to forecast the end-of-period exchange rate. Here is the relevant passage from the instructions:

I am interested in your forecasts of the exchange rate in each period. The exchange rate is the price of the red asset divided by the price of the blue asset. So if you think the red asset is going to trade for $\$ 3.75$ in period one and the blue asset is going to trade for $\$ 3.75$ in period one, then you should write down an exchange rate forecast of $\$ 3.75 / \$ 3.75=1.0$. Or if you the red asset will be more expensive than the blue asset, then you should write down an exchange rate forecast bigger than one. If you think the red asset is going to trade for less than the blue asset, then write down an exchange rate that is smaller than one.

The price of an asset is the average price of the transactions that occur in that period. If there is no transaction, then the price of an asset is halfway between the outstanding bid and offer prices. If there is no bid-offer spread, then the price of an asset is what it was in the last period. These are the rules that we use to calculate the actual exchange rate in each period.

Before each period, we will give you a little piece of paper for your exchange rate forecast. Write your trader number and your forecast, and we will record all the forecasts on our master sheet. The best forecaster will earn an extra dollar at the end of the experiment. Remember, the exchange rate is the price of the red asset divided by the price of the blue asset. If you think the red asset is going to trade at a higher price than the blue asset, then you should write down some number that is bigger than one for the exchange rate. We will keep a running tally on the blackboard of the past exchange rates for your convenience.

\section{EXPERIMENTAL RESULTS}

Figures 1-6 use transactions to show the average of the $\left(p_{t, j}-f_{t, j}\right) / f_{t, j}$, the percentage that the price exceeds the fundamental in each asset market in each of period. In case there was no transaction, we report the midpoint of the final bid-offer spread, and if there is no bid-offer spread, we show a bubble component of zero. ${ }^{9}$

These figures provide overwhelming evidence that bubbles occur in both markets in every treatment. Also, it is clear that the bubbles in the blue and red markets are positively correlated within almost every session. The three

\footnotetext{
${ }^{9}$ In the third repetition of design 6 , there were seven times when there was no bid-offer spread in either market. In all other sessions, there were transactions or bid-offer spreads in both markets in every period.
} 


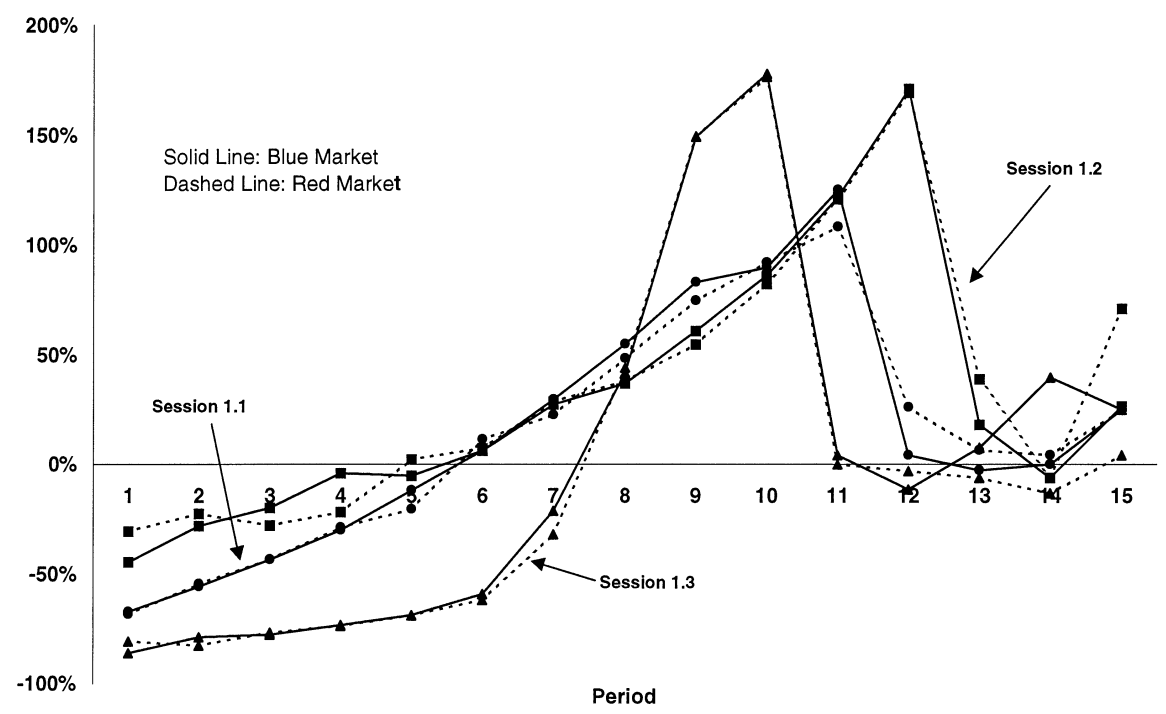

Figure 1. Bubble component for design 1 as a percentage deviation from the predicted asset price

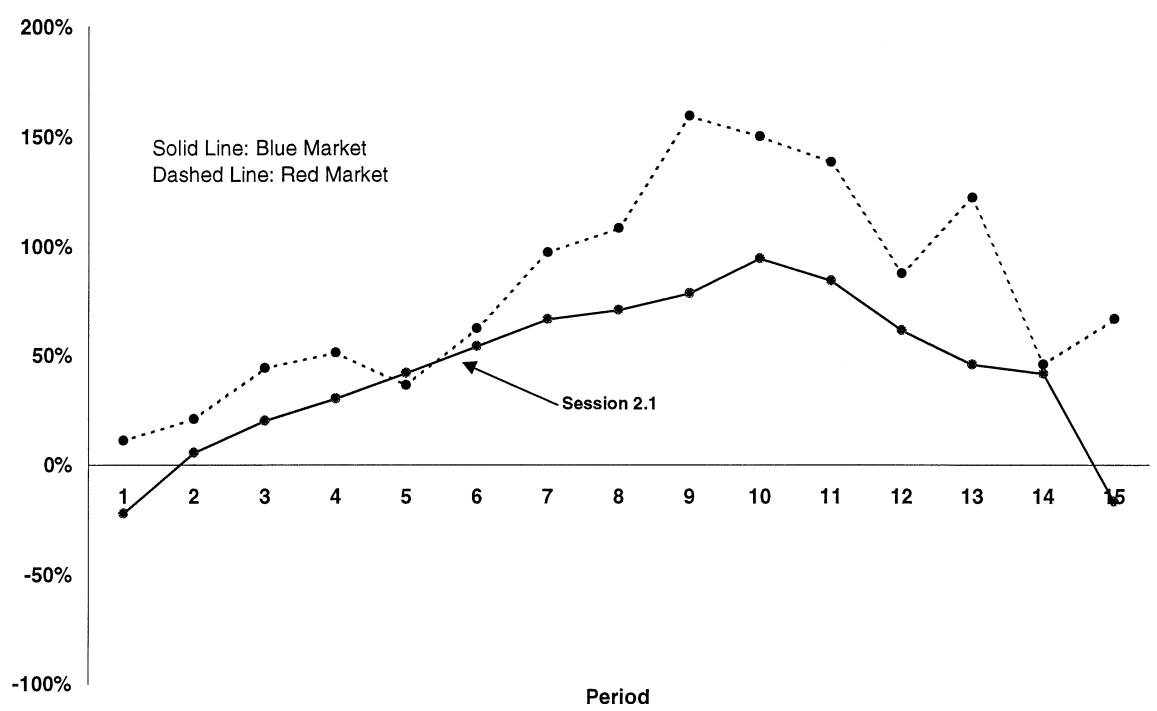

Figure 2. Bubble component for design 2 as a percentage deviation from the predicted asset price 


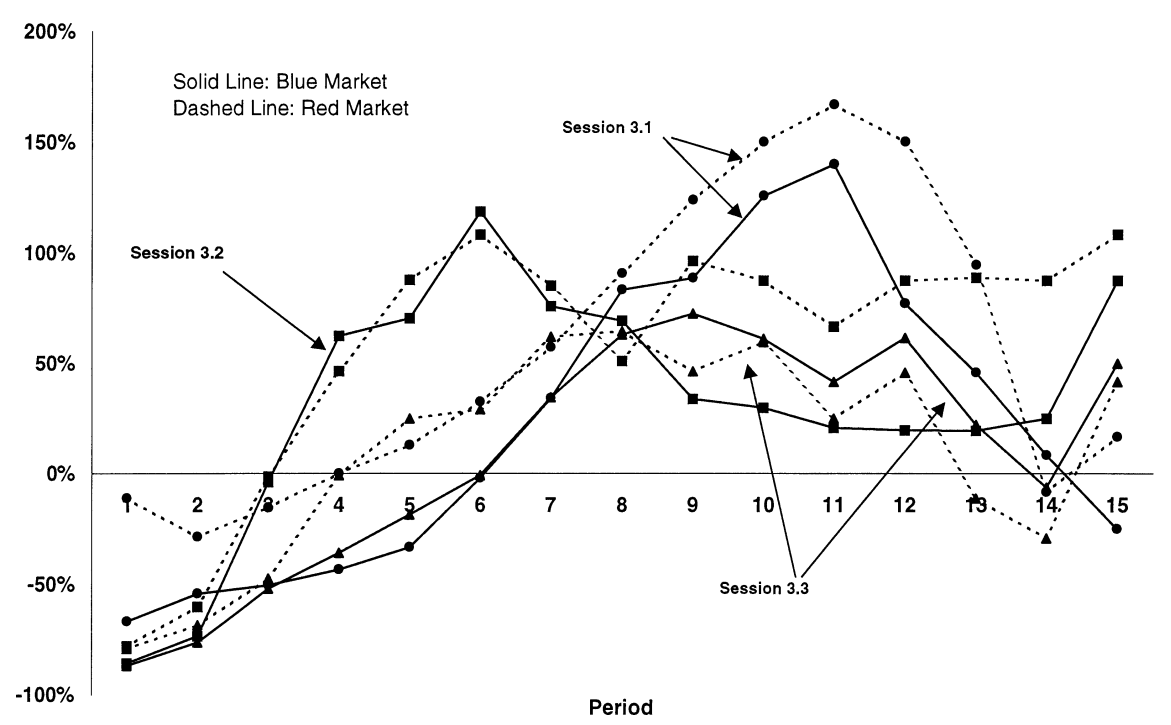

Figure 3. Bubble component for design 3 as a percentage deviation from the predicted asset price

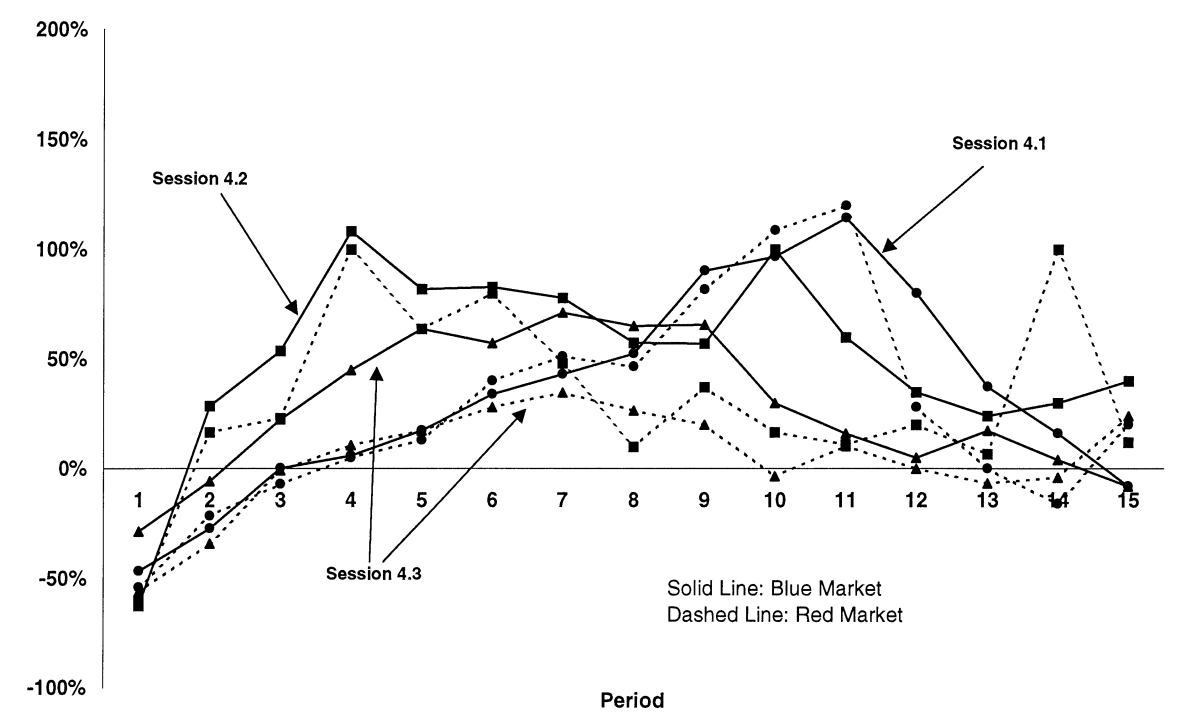

Figure 4. Bubble component for design 4 as a percentage deviation from the predicted asset price 


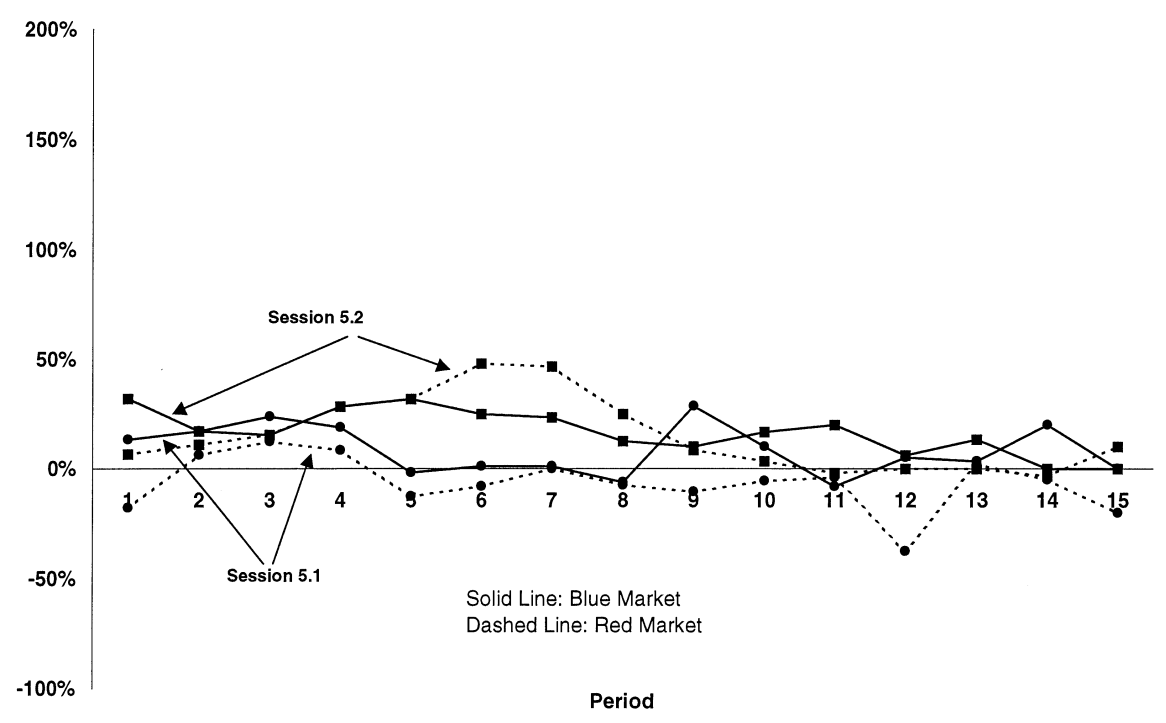

Figure 5. Bubble component for design 5 as a percentage deviation from the predicted asset price

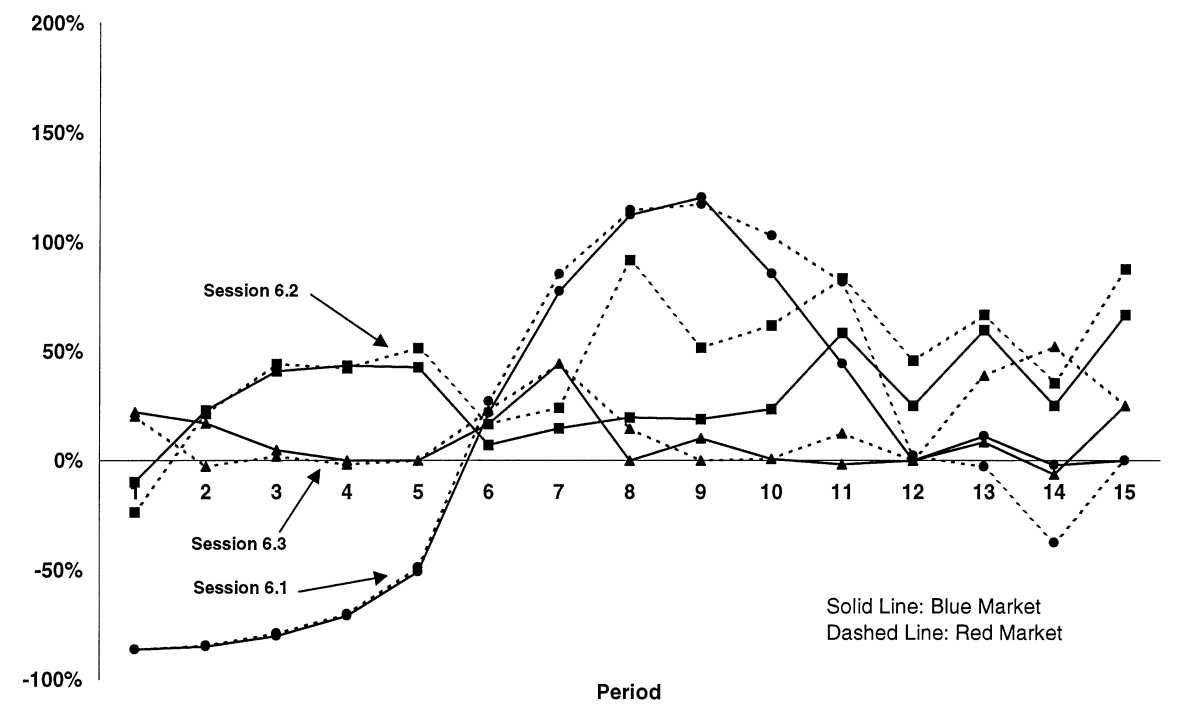

Figure 6. Bubble component for design 6 as a percentage deviation from the predicted asset price 
replications of design 1 show the blue and red markets exhibiting nearly identical bubbles. In design 2, the blue- and red-market bubbles coincide, although the extent of the bubble in the blue market is not as pronounced as that in the red market. In designs 3 and 4, the bubbles in the three sessions of each design peak at different times; but for each session, the blue-market and red-market bubbles move closely together. In design 5, in which traders were asked to make exchange rate forecasts, the prices in the blue and red markets again tended to move together, but did not generate the bubbles seen in the previous sessions. Finally, in the design 6 session with inexperienced traders, the blue- and red-market bubbles were pronounced and coincident. As experience increased, the bubbles flattened and disappeared.

There were 891 transactions across both markets in all 15 of these sessions. Furthermore, 807 of these transactions occurred after the first periods of these sessions. The frequency of bubbles in the sessions described in figures $1-6$ and the frequency with which trades occurred after the first trading period provide strong evidence that Hypothesis 1, based on Bayesian agents with common priors, holding rational expectations, can be rejected. Bubbles will occur in these asset markets. The important findings of Smith et al. (1988) are robust with respect to trading in multiple asset markets. ${ }^{10}$

Recall that the exchange rate is the relative price of the red asset in terms of the blue. Now let $e_{t}^{i}$ be the observed exchange rate in period $t$ in session $i$ and $e^{i}$ be the theoretical (constant) value of the exchange rate in that session. Further, for all the sessions $i=1, \ldots, n_{k}$ in a given design $k=1, \ldots, 6$, consider

$$
u_{t}^{k}=\left(1 / n_{k}\right) \sum_{i=1}^{n_{k}}\left(e_{t}^{i}-e^{i}\right) / e^{i}
$$

as the average normalized exchange rate prediction error in each period. This normalization makes the exchange rates comparable across designs and time and similar to the bubble components of the asset prices. Figures 7 and 8 graph these data and bear directly upon Hypothesis 2 .

Figures 1-8 are graphed with the same scales on the vertical axes and the same scales on the horizontal axes. Two aspects of these data are salient. First, these deviations are much smaller than the asset price deviations. Second, there are no bubbles in these cross exchange rates comparable to the bubbles in the asset price data. These two observations support Hypothesis 2: The cross exchange rate is near its theoretical value. This occurs even though there are obvious bubbles in the individual asset prices. Of course, this conclusion must be tempered somewhat. The deviations in designs 2 and 3 , when $e^{i}=0.5$, are larger than those for the cognitively simpler cases in designs $1,4,5$ and 6 , when $e^{i}=1$. Still, figure 8 shows a strong tendency for the average exchange rate deviation in design 3 to converge quickly towards its theoretical value, even though there were bubbles in every market in each session!

\footnotetext{
${ }^{10}$ This line of research refutes the assumptions implicit in Tirole's (1982, Proposition 3) analysis of finite bubbles. Either some traders are not risk-neutral or myopic rational expectations are not germane here.
} 


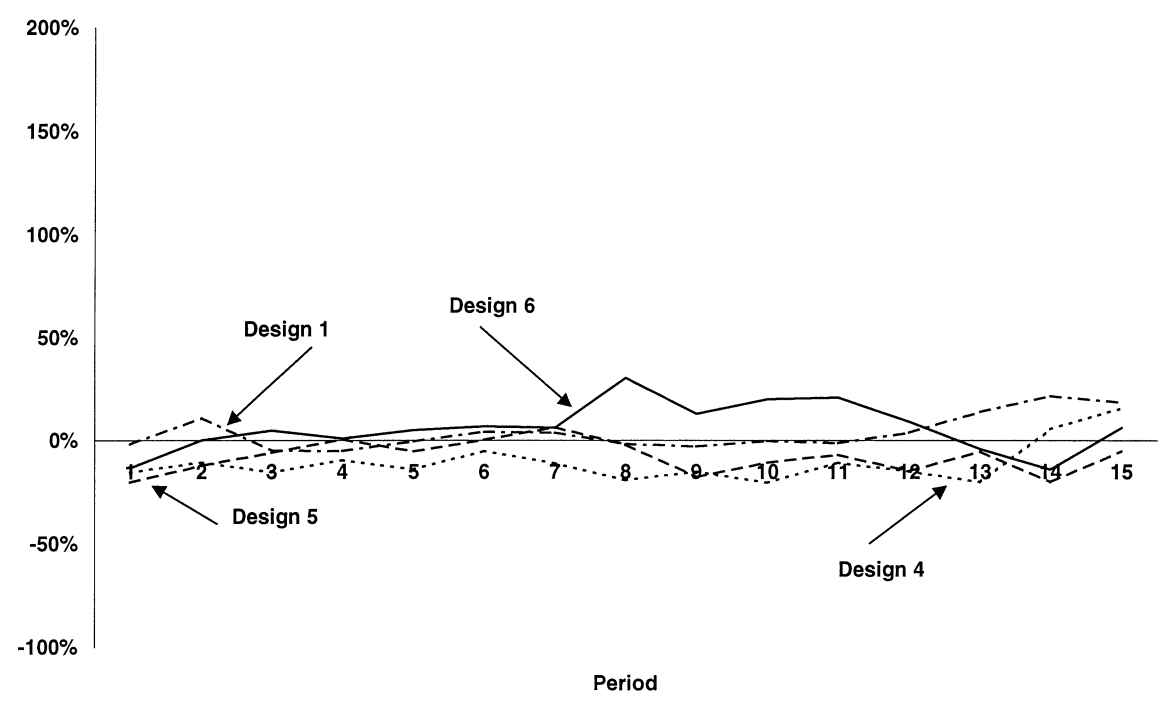

Figure 7. Average exchange rate bubbles measured as percentage deviations from the predicted exchange rate when the predicted risk-neutral exchange rate is 1

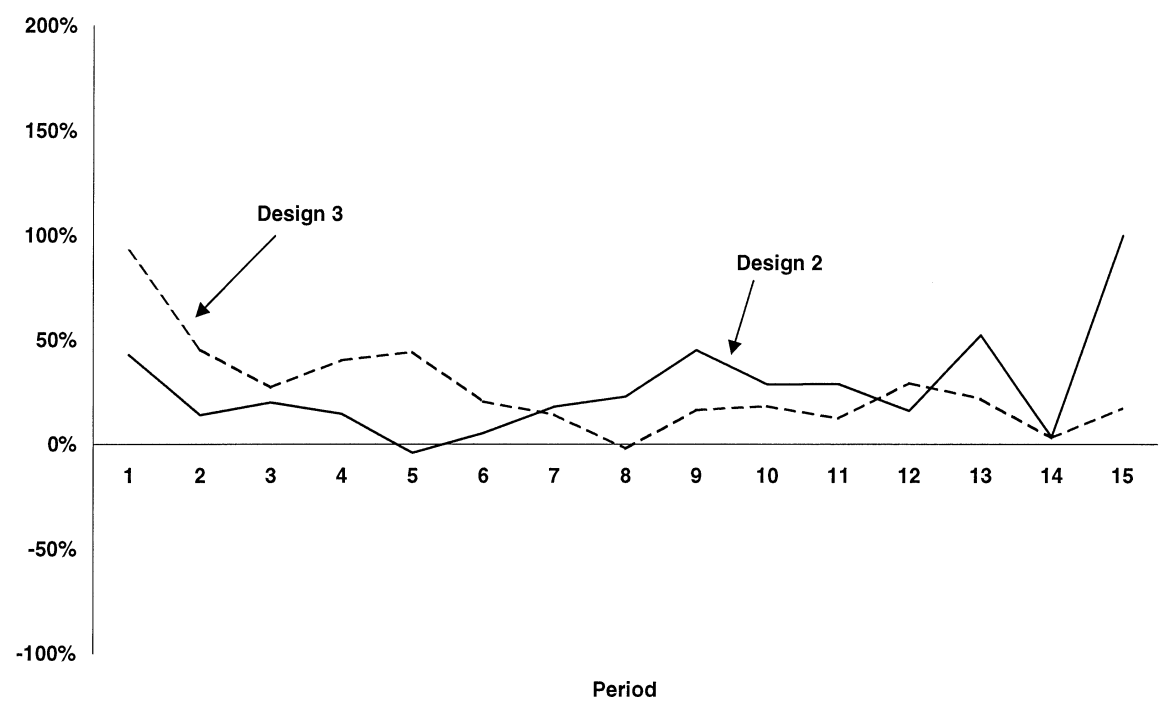

Figure 8. Average exchange rate bubbles measured as percentage deviations from the predicted exchange rate when the predicted risk-neutral exchange rate is 0.5 
Hypothesis 3 claims that the bubbles in asset markets will be comparable under fixed and flexible exchange rates. This hypothesis cannot be supported by the data from the sessions reported here. Figure 2 shows the bubble resulting from a fixed exchange rate session. The bubble begins early in the session and prices continue to rise until the tenth trading period in the red market. Not until the twelfth period is there a substantial drop in price. In the blue market, the bubble extends through the fourteenth period, peaking in the tenth period. The two bubbles' periods coincide although their amplitudes are different. Figure 3 shows the time series from three sessions with the same underlying parameters as in figure 2, only the exchange rate is not fixed at 0.5 . The theoretical exchange rate is, however, 0.5 . There are bubbles in all three sessions, and the blue- and red-market bubble tend to coincide in each session. However in session 3.1 the peak price is reached in period 11 for both assets, while in session 3.2 the peak price is reached in period 6 for both assets but the red asset price tends to level out at its period10 value as the blue asset drops steadily until the fifteenth period. In session 3.3 the red market peaks in period 8 while the blue market peaks in the ninth period. Both markets then experience price declines until the fifteenth period. Hence, these results cannot support the hypothesis that there is no difference in the pattern of bubbles in environments with fixed and flexible exchange rates. Still, we are not want to draw any strong conclusions because there was only one session in design 2, and it did not explicitly control for the effect of trader experience.

Now consider

$$
u^{i}=(1 / T) \sum_{t=1}^{T}\left(e_{t}^{i}-e^{i}\right) / e^{i}
$$

the overall normalized exchange rate deviation in session $i$. Table 2 gives these data and bears on Hypothesis 4 which states that there is an exchange rate risk premium.

In designs 4 and 5, the blue asset was riskier than the red, but the red asset typically traded at a discount! The expected normalized exchange rate deviation

Table 2. Normalized exchange rate deviation $u^{i}$

\begin{tabular}{lrrr}
\hline \multicolumn{2}{c}{ Sessions without a risky asset } & & \multicolumn{2}{c}{ Sessions with a risky asset } \\
\hline 1.1 & $1 \%$ & 4.1 & $-4 \%$ \\
1.2 & $4 \%$ & 4.2 & $-11 \%$ \\
1.3 & $7 \%$ & 4.3 & $-17 \%$ \\
2.1 & $27 \%$ & 5.1 & $-11 \%$ \\
3.1 & $43 \%$ & 5.2 & \\
3.2 & $26 \%$ & & \\
3.3 & $11 \%$ & & \\
6.1 & $1 \%$ & & \\
6.2 & $11 \%$ & & \\
6.3 & $3 \%$ & & \\
\hline
\end{tabular}


for designs 4 and 5 are expected to be greater than those for the other designs. Using a Wilcoxon-Mann-Whitney statistic, the null hypothesis of no difference between the sessions with the risky asset and the sessions without the risky asset cannot be rejected in favor of the alternative that the $u^{i}$ for designs 4 and 5 sessions exceed those of the other sessions (one-tailed test, $p=0.997$ ). ${ }^{11}$ However, given that we observe a clear difference between the values in the right and left columns of table 2, the Wilcoxon-Mann-Whitney test used descriptively permits the rejection of the null hypothesis that the two distributions of $u^{i}$ coincide against the alternative that they do not (two-tailed test, $p=0.006$ ). This provides support for Hypothesis 4 that there is an exchange-rate risk premium. Indeed, there is evidence for risk-loving behavior in these markets. This finding is in accord with the work of Ang and Schwartz (1992), who show that traders seek to purchase risky assets. This result may have important implications because it establishes a link between (rational) speculative behavior and the actual risk of two different currencies.

Hypothesis 5 was proposed partly to replicate the central finding of Smith et al. (1988). Consider regressions based on the following model: ${ }^{12}$

$$
\left(P_{t}-P_{t-1}\right)=\alpha+\beta X_{t-1}+\varepsilon_{t}
$$

where $P_{t}$ is a $2 \times 1$ vector of the average blue and red asset price in period $t,{ }^{13} \alpha$ is a $2 \times 1$ vector of constants, $\beta$ is a $2 \times 2$ matrix capturing own-market and cross-market effects, $X_{t-1}$ is the $2 \times 1$ vector of the excess of bids over offers in the blue and red markets in period $t-1$, and $\varepsilon_{t}$ is a $2 \times 1$ vector of idiosyncratic errors. Using the technique of seemingly unrelated regressions, we estimated the two equations in (2) on data from periods 2 through 15.

Table 3 presents the regression coefficients, and it shows when the asymptotic standard errors warrant rejection of the relevant null hypotheses. These are that the constant captures the change in the fundamentals from period to period $(-0.24,-0.25$ or -0.12 , according to the design) and that the lagged excess demands have no effects. This table also presents summary statistics for each session based upon the null hypothesis that all six estimated coefficients in the system (2) are equal to zero.

Note that average asset prices generally decline at the rate of change comparable to the fundamental. Also, the summary statistics show that the simple model based upon equation (2) fits these data quite well. Still, these effects seem to obey no pattern of cross-equation restrictions. Only in one session (3.1) does the blue asset's lagged excess demand affect only the blue asset's price change. In no session does the red asset's lagged excess demand affect only the red asset's price change. Excess demand in the blue market is

\footnotetext{
${ }^{11}$ The null hypothesis is that there is no difference in the median of these deviations between the sessions in designs 1, 2, 3 and 6 and those in designs 4 and 5. The alternative is that the deviations in designs 4 and 5 are greater because the red asset is safer than the blue. Thus a one-tailed test is appropriate.

${ }^{12}$ Session 6.3 had too few transactions to allow for meaningful analysis.

${ }^{13}$ If there was no transaction in a market in period $t$, we used the midpoint of the final bid-offer spread.
} 
Table 3. Effects of lagged excess demands

\begin{tabular}{|c|c|c|c|c|c|c|}
\hline Session & $\begin{array}{l}\text { Asset price } \\
\text { change }\end{array}$ & $\begin{array}{l}\text { Predicted } \\
\text { constant }\end{array}$ & Constant & $\begin{array}{l}\text { Lagged blue market } \\
\text { excess demand }\end{array}$ & $\begin{array}{l}\text { Lagged red market } \\
\text { excess demand }\end{array}$ & $\begin{array}{l}\text { F-statistic } \\
(p \text {-value })\end{array}$ \\
\hline 1.1 & Blue & -0.24 & -0.272 & 0.038 & 0.043 & 4.304 \\
\hline 1.1 & Red & -0.24 & -0.262 & $0.066^{* *}$ & 0.018 & $(0.01)$ \\
\hline 1.2 & Blue & -0.24 & -0.255 & 0.032 & 0.009 & 3.186 \\
\hline 1.2 & Red & -0.24 & -0.291 & $0.062^{* *}$ & -0.040 & $(0.02)$ \\
\hline 1.3 & Blue & -0.24 & -0.418 & $0.077^{*}$ & 0.032 & 2.769 \\
\hline 1.3 & Red & -0.24 & -0.399 & 0.064 & 0.044 & $(0.04)$ \\
\hline 2.1 & Blue & -0.24 & -0.228 & 0.019 & 0.020 & 1.999 \\
\hline 2.1 & Red & -0.12 & -0.161 & 0.009 & 0.015 & $(0.10)$ \\
\hline 3.1 & Blue & -0.24 & -0.281 & $0.041^{* *}$ & -0.003 & 4.811 \\
\hline 3.1 & Red & -0.12 & -0.205 & $-0.019^{* *}$ & -0.004 & $(0.00)$ \\
\hline 3.2 & Blue & -0.24 & $-0.725^{* *}$ & $0.124^{* *}$ & $0.137^{* *}$ & 6.437 \\
\hline 3.2 & Red & -0.12 & -0.251 & $0.055^{* *}$ & 0.024 & $(0.00)$ \\
\hline 3.3 & Blue & -0.24 & $-0.058^{* *}$ & 0.014 & $0.062^{* *}$ & 6.130 \\
\hline 3.3 & Red & -0.12 & -0.042 & 0.015 & $0.030^{*}$ & $(0.00)$ \\
\hline 4.1 & Blue & -0.25 & -0.222 & 0.002 & $0.041^{* *}$ & 3.069 \\
\hline 4.1 & Red & -0.25 & -0.190 & -0.012 & $0.053^{*}$ & $(0.02)$ \\
\hline 4.2 & Blue & -0.25 & -0.524 & -0.008 & $0.103^{* *}$ & 1.719 \\
\hline 4.2 & Red & -0.25 & -0.463 & -0.017 & $0.096^{*}$ & $(0.16)$ \\
\hline 4.3 & Blue & -0.25 & -0.227 & $0.055^{* *}$ & -0.028 & 3.053 \\
\hline 4.3 & Red & -0.25 & -0.119 & $0.048^{* *}$ & -0.031 & $(0.03)$ \\
\hline 5.1 & Blue & -0.25 & -0.285 & 0.028 & -0.004 & 6.198 \\
\hline 5.1 & Red & -0.25 & -0.288 & $0.032^{* *}$ & $0.044^{* *}$ & $(0.00)$ \\
\hline 5.2 & Blue & -0.25 & -0.384 & 0.013 & $0.025^{*}$ & 8.287 \\
\hline 5.2 & Red & -0.25 & -0.082 & $-0.034^{*}$ & $0.024^{*}$ & $(0.00)$ \\
\hline 6.1 & Blue & -0.24 & -0.180 & 0.014 & $0.062^{* *}$ & 17.58 \\
\hline 6.1 & Red & -0.24 & -0.224 & -0.014 & $0.094^{* *}$ & $(0.00)$ \\
\hline 6.2 & Blue & -0.24 & -0.364 & 0.007 & $0.049^{* *}$ & 2.85 \\
\hline 6.2 & Red & -0.24 & -0.348 & 0.000 & 0.058 & $(0.03)$ \\
\hline
\end{tabular}

Note: A single asterisk indicates statistical significance at the $95 \%$ confidence level and a double asterisk at the $99 \%$ confidence level.

occasionally significantly related to asset bubbles in both markets, and also excess demand in the red market frequently shows a similar property. In 8 of the 14 sessions reported on table 3, either the blue asset's lagged excess demand affects both asset price changes or the red asset's lagged excess demand affects both asset price changes (in all of these instances affected is identified as a statistically significant coefficient). We conclude tentatively that activity in one market often seems to have a predominant effect in causing bubbles in both markets. This conclusion is consistent with the findings of Engle et al. (1990), who examined whether foreign exchange markets were subject to heat waves (country-specific shocks) or meteor showers (intra-day volatility that spilled over from one financial center to another). Those authors found evidence against their notion of heat waves, and the lack of market-specific bubbles in these sessions thus corroborates what those authors found in the field.

Hypothesis 6 explores the pattern of bids and offers in each of the sessions. If bids and offers occur randomly in the blue and red markets, then the null hypothesis for a runs test is applicable. Table 4 presents tests based upon the 
large sample normal approximation of a standard test for randomness. ${ }^{14}$ In 14 sessions, we observe significantly too few runs, indicating longer than expected strings of bids and offers in one market. Hence, there seem to be streaks of bids and offers in one market and then streaks of activity in the other market. The null, however, cannot be rejected in session 6.3, suggesting that repeated interaction between the same group of experienced traders increases the likelihood that observations fall randomly across markets.

Hypothesis 7 examines whether repeated interaction between the same group of traders mitigates the effect of bubbles. The use of the same group of subjects entails that the dividend processes and the aggregate effects of the individuals' trading strategies eventually becomes common knowledge. There were 94 transactions in both markets in the session 6.1, and 30 such transactions in the session 6.3; reduced volume is prima-facie evidence that the effects of bubbles have been attenuated. Also, figure 6 shows that bubbles occur in neither market in session 6.3 (the time series identified with triangles). Hence, there is strong evidence confirming that the repeated use of the same group of traders mitigates bubbles.

Hypothesis 8 gets at the essence of whether the subjects' exchange rate forecasts are unbiased. The hypothesis is a stronger test than can be conducted using field data because we have the entire population of exchange rate forecasts for every market participant in the two sessions in design 5. Figures 9 and 10 graph the exchange rate forecasts. These figures show the maximal,

Table 4. Do bids and offers fall randomly across markets?

\begin{tabular}{ll}
\hline Session & Test statistic \\
\hline 1.1 & $8.108^{* *}$ \\
1.2 & $5.894^{* *}$ \\
1.3 & $9.465^{* *}$ \\
2.1 & $8.474^{* *}$ \\
3.1 & $3.773^{* *}$ \\
3.2 & $5.517^{* *}$ \\
3.3 & $2.126^{*}$ \\
4.1 & $3.543^{* *}$ \\
4.2 & $6.548^{* *}$ \\
4.3 & $3.898^{* *}$ \\
5.1 & $5.411^{* *}$ \\
5.2 & $3.176^{* *}$ \\
6.1 & $6.255^{* *}$ \\
6.2 & $4.370^{* *}$ \\
6.3 & 0.525
\end{tabular}

Note: A single asterisk indicates statistical significance at the $95 \%$ confidence level and a double asterisk at the $99 \%$ confidence level.

\footnotetext{
${ }^{14}$ See Bradley (1968, p. 261). We define a run as a streak of bids and offers limited to any one market, even if that run occurs over two or more periods.
} 


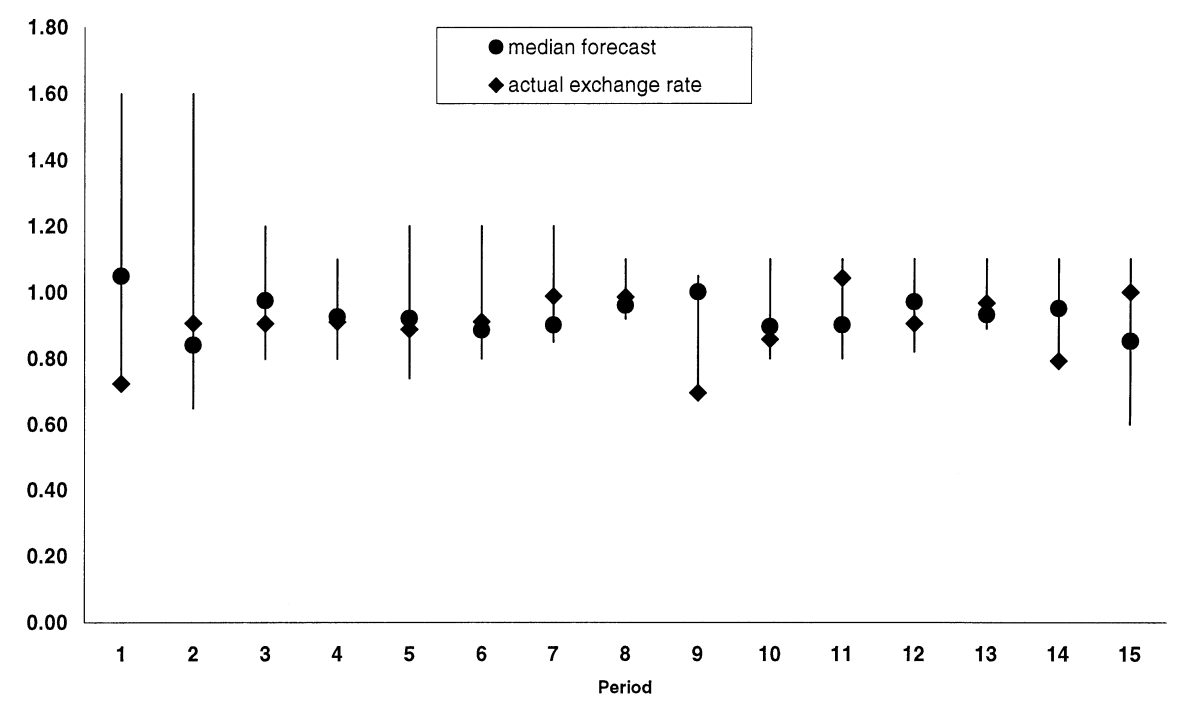

Figure 9. Average exchange rates and ranges and medians of exchange rate forecasts by period for session 5.1

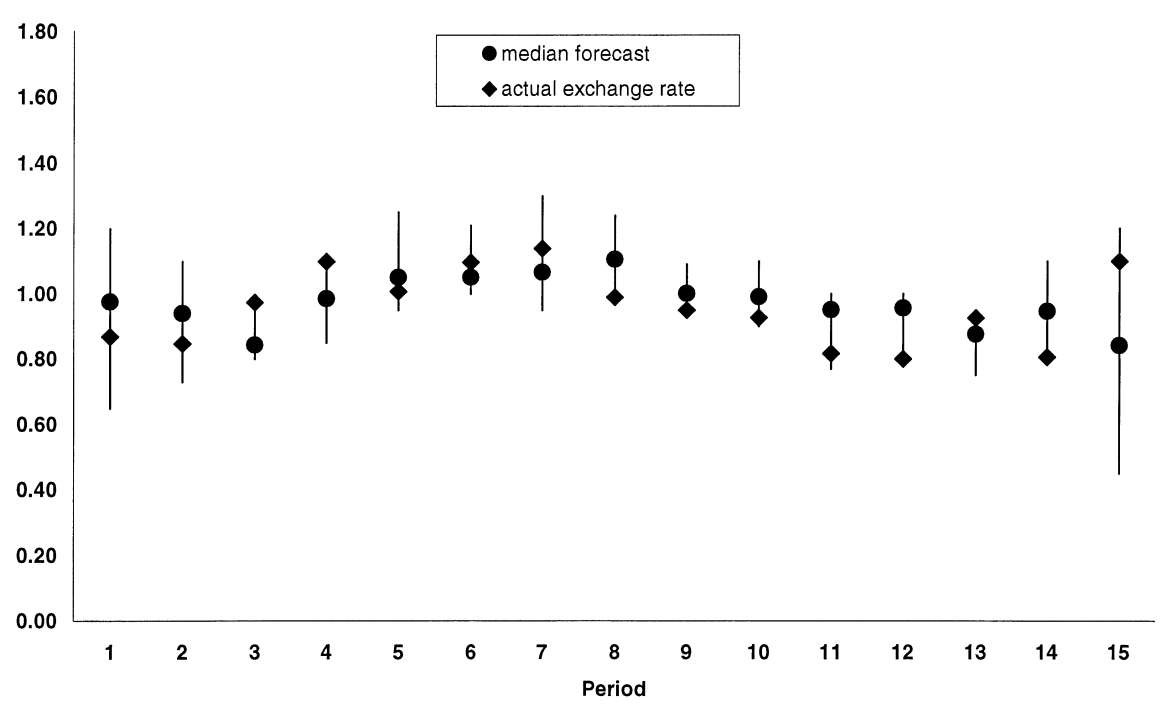

Figure 10. Actual exchange rates and ranges and medians of exchange rate forecasts by period for session 5.2 
minimal, and median forecasts of the 12 subjects in all 15 periods, and they give the actual value of exchange rate. The median forecast is a fairly good predictor. Also, we conducted simple sign tests of size one percent to see which subjects were accurate forecasters. ${ }^{15}$ All but two of the 24 traders had accurate forecasts. This is strong evidence in favor of the rationality of these traders. Of course, the great anomaly here is that these traders are rational about crosscurrency arbitrage while participating in markets where asset prices deviate quite a bit from their fundamental values! ${ }^{16}$

\section{CONCLUSIONS}

We have conducted one of the first analyses of foreign exchange markets in the laboratory. Although truly dynamic experimental asset markets almost uniformly give rise to bubbles, the relationship between the blue and red asset markets conformed largely to the predictions of simple economic theory. Our evidence shows an interesting amalgam of rational behavior in markets with strong speculative elements. The subjects in these sessions did seem to have a slight preference for risky assets, and they were able largely to perceive the effects that their behavior had on the asset markets in which they traded. We were disappointed that the variability in the bubbles in the fixed and flexible rate designs did not permit us to distinguish between these treatments. The use of an underlying exchange rate that differed from unity (as in design 1) may have added to the variability of the peaks in the bubbles. This in itself is an observation that merits further investigation. Perhaps asset returns themselves are more variable in a system of flexible rates. Whether a system of flexible exchange rates gives rise to speculation is worth analyzing more closely in future research.

The regressions in table 3 indicate that one market tended to drive the bubbles in both markets, but it is impossible to predict whether excess demand for assets in the blue market or the red market drove the bubble in both markets. This finding provides a potential explanation for contagion effects in foreign exchange markets in the field; using an ad hoc definition of a currency crisis in an atheoretical econometric investigation, Eichengreen et al. (1996) found surprisingly strong contagion effects across exchange rate markets. Our experiments confirm these findings, and point to a potential underlying

\footnotetext{
${ }^{15}$ The sign test is based upon the null hypothesis that each agent's forecast is an unbiased predictor of the median of the exchange rate distribution in each period. In theory, each subject's forecast errors may be correlated across periods, but for no subject was the correlation between the current forecast error and its lagged value significant.

${ }^{16}$ Peterson (1993) showed that traders made biased predictions of one asset's price in sessions related to ours. He too concluded that traders' forecasts are not consistent with risk-neutral rational expectations equilibrium. Frankel and Froot (1987) found significant bias in the exchange rate predictions of foreign exchange traders in the field. Also, in later work, Frankel and Froot (1989) conducted a careful study of relationship between traders' forecasts and the risk premium in markets in the field. Adjusting for the risk premium, they were able to reject the notion of unbiased forecasts in favor of one of excessive speculation.
} 
theoretical mechanism: the bursting of a bubble in one asset market makes agents in all markets update their beliefs about the key currency radically.

Finally, our subjects performed well at forecasting exchange rates. Even forecasting one period ahead is not a trivial exercise when it is apparent that each trader's subjective expectations of market activity influence asset prices. Still, our subjects were remarkably good (occasionally risk-loving) forecasters in markets where uncertainty about others' trading strategies has a predominant influence on asset prices.

\section{REFERENCES}

Ang, J. S. and T. V. Schwartz (1992) "The Formation and Control of Asset Bubbles: An Experimental Study," unpublished manuscript, Florida State University.

Arifovic, J. (1996) "The Behavior of the Exchange Rate in the Genetic Algorithm and Experimental Economies," Journal of Political Economy 104, 510-41.

Bradley, J. V. (1968) Distribution-Free Statistical Tests, New York: Prentice-Hall.

Chorafas, D. N. (1992) Treasury Operations and the Foreign Exchange Challenge: A Guide to Risk Management Strategies for the New World Markets, New York: John Wiley.

Davis, D. D. and C. A. Holt (1993) Experimental Economics, Princeton: Princeton University Press.

Eichengreen, B., A. Rose and C. Wyplosz (1996) "Contagious Currency Crises: First Tests," Scandinavian Journal of Economic 98, 463-84.

Engle, R. F., T. Ito, and W. Lin (1990) "Meteor Showers or Heat Waves? Heteroskedastic IntraDaily Volatility in the Foreign Exchange Market," Econometrica 58, 525-42.

Fisher, E. O’N. (1998) "Explaining Bubbles in Experimental Asset Markets," unpublished manuscript, Ohio State University.

Fisher, E. O'N. and J. Y. Park (1991) "Testing Purchasing Power Parity under the Null Hypothesis of Co-integration," Economic Journal 101, 1476-84.

Flood, R. P. and R. J. Hodrick (1990) "On Testing for Speculative Bubbles," Journal of Economic Perspectives 4, 85-101.

Forsythe, R., T. R. Palfrey and C. R. Plott (1982) “Asset Valuation in an Experimental Market," Econometrica 50, 537-67.

Frankel, J. A. and K. A. Froot (1987) "Using Survey Data to Test Standard Propositions Regarding Exchange Rate Expectations," American Economic Review 77, 133-53.

— (1989) "Forward Discount Bias: Is it an Exchange Risk Premium?," Quarterly Journal of Economics 104, 139-61.

Friedman, M. (1953) "The Case for Flexible Exchange Rates," in Essays in Positive Economics, Chicago: University of Chicago Press.

Grabbe, J. O. (1986) International Financial Markets, New York: Elsevier.

King, R., V. Smith, A. Williams and M. van Boening (1993) "The Robustness of Bubbles and Crashes in Experimental Spot Markets," in I. Prigogine, R. H. Day and P. Chen (eds), Nonlinear Dynamics and Evolutionary Economics, Oxford: Oxford University Press.

Mark, N. C. (1990) "Real and Nominal Exchange Rates in the Long Run: An Empirical Investigation," Journal of International Economics 28, 115-36.

Milgrom, P. and N. Stokey (1982) "Information, Trade and Common Knowledge," Journal of Economic Theory 26, 17-27.

Noussair, C. N., C. Plott and R. Riezman (1997) "The Principles of Exchange Rate Determination in an International Finance Experiment," Journal of Political Economy 105, 822-61.

O’Brien, J. and S. Srivastava (1991) "Dynamic Stock Markets with Multiple Assets: An Experimental Analysis," Journal of Finance 46, 1811-38.

Peterson, S. P. (1993) "Forecasting Dynamics and Convergence to Market Fundamentals: Evidence from Experimental Asset Markets," Journal of Economic Behavior and Organization 22, 269-84.

Plott, C. R. and S. Sunder (1982) "Efficiency of Experimental Securities Markets with Insider Information: An Application of Rational-Expectations Models," Journal of Political Economy 92, 663-98.

(1988) "Rational Expectations and the Aggregation of Diverse Information in Laboratory Security Markets," Econometrica 56, 1085-118. 
Smith, V. G. L. Suchanek and A. W., Williams (1988) "Bubbles, Crashes, and Endogenous Expectations in Experimental Asset Markets," Econometrica 56, 1119-52.

Sunder, S. (1995) "Experimental Asset Markets: A Survey," in J. H. Kagel and A. Roth (eds), The Handbook of Experimental Economics, Princeton: Princeton University Press.

Tirole, J. (1982) "On the Possibility of Speculation Under Rational Expectations," Econometrica $50,1163-82$.

van Boening, M. V., A. W. Williams and S. LaMaster (1993) "Price Bubbles and Crashes in Experimental Call Markets," Economics Letters 41, 179-85. 